\title{
Genome of Epinotia aporema granulovirus (EpapGV), a polyorganotropic fast killing betabaculovirus with a novel thymidylate kinase gene
}

María Leticia Ferrelli ${ }^{1}$, Ricardo Salvador ${ }^{1,2}$, Marina Elizabeth Biedma ${ }^{1,4}$, Marcelo Facundo Berretta ${ }^{2}$, Santiago Haase ${ }^{1}$, Alicia Sciocco-Cap ${ }^{2}$, Pablo Daniel Ghiringhelli ${ }^{3}$ and Víctor Romanowski ${ }^{*}$

\begin{abstract}
Background: Epinotia aporema (Lepidoptera: Tortricidae) is an important pest of legume crops in South America. Epinotia aporema granulovirus (EpapGV) is a baculovirus that causes a polyorganotropic infection in the host larva. Its high pathogenicity and host specificity make EpapGV an excellent candidate to be used as a biological control agent.

Results: The genome of Epinotia aporema granulovirus (EpapGV) was sequenced and analyzed. Its circular double-stranded DNA genome is 119,082 bp in length and codes for 133 putative genes. It contains the 31 baculovirus core genes and a set of 19 genes that are GV exclusive. Seventeen ORFs were unique to EpapGV in comparison with other baculoviruses. Of these, 16 found no homologues in GenBank, and one encoded a thymidylate kinase. Analysis of nucleotide sequence repeats revealed the presence of 16 homologous regions (hrs) interspersed throughout the genome. Each $h r$ was characterized by the presence of 1 to 3 clustered imperfect palindromes which are similar to previously described palindromes of tortricid-specific GVs. Also, one of the hrs (hr4) has flanking sequences suggestive of a putative non-hr ori. Interestingly, two more complex hrs were found in opposite loci, dividing the circular dsDNA genome in two halves. Gene synteny maps showed the great colinearity of sequenced GVs, being EpapGV the most dissimilar as it has a $20 \mathrm{~kb}$-long gene block inversion. Phylogenetic study performed with 31 core genes of 58 baculoviral genomes suggests that EpapGV is the baculovirus isolate closest to the putative common ancestor of tortricid specific betabaculoviruses.

Conclusions: This study, along with previous characterization of EpapGV infection, is useful for the better understanding of the pathology caused by this virus and its potential utilization as a bioinsecticide.
\end{abstract}

\section{Background}

Baculoviruses (family Baculoviridae) are rod-shaped, enveloped, insect-specific viruses with double-stranded, circular DNA genomes ranging in size from 80 to $180 \mathrm{~kb}$ [1]. The family Baculoviridae is subdivided into four genera: Alphabaculovirus (lepidopteran-specific nucleopolyhedrovirus, NPVs), Betabaculovirus (lepidopteran-specific granulovirus, GVs), Gammabaculovirus (hymenopteran-specific NPVs) and Deltabaculovirus

\footnotetext{
* Correspondence: victor@biol.unlp.edu.ar

${ }^{1}$ Instituto de Biotecnología y Biología Molecular, Facultad de Ciencias Exactas, Universidad Nacional de La Plata, CONICET, La Plata, Argentina

Full list of author information is available at the end of the article
}

(dipteran-specific NPV) [2,3]. GVs have been isolated only from insects belonging to the order Lepidoptera and are classified in three groups according to the pathology caused in their insect hosts. Type 1 pathology is characterized by an infection limited to the host's midgut and fat body resulting in a relatively slow speed of kill. Type 2 pathology is characterized by infection of most of the host's tissues and a rapid speed of kill. There is a third pathology with a single representative, the Harrisina brillians granulovirus, that causes an infection constrained to the midgut epithelium that results in the rapid death of the host [4].

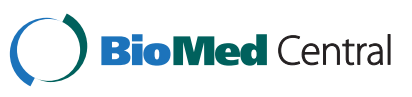


A highly pathogenic granulovirus was isolated from a larva of the "bean shoot borer" Epinotia aporema (Lepidoptera: Tortricidae), one of the major soybean pests in Argentina, and characterized at biological and molecular levels [5]. Further characterization of its pathology demonstrated that this virus belongs to the type 2 GVs meaning that the infection caused by EpapGV in its host is polyorganotropic [6]. All this information has been instrumental to formally propose its use as a microbial control agent with great potential. In order to contribute to a more thorough characterization of EpapGV we set out to determine and analyze its complete genome sequence.

To date, close to 60 baculovirus genomes have been fully sequenced, 12 of them belong to the Betabaculovirus genus. Completely sequenced GVs are listed in Table 1 and their pathology types are indicated. In this report, we present the complete sequence and organization of the EpapGV genome and compare them to other baculoviruses using genomic and phylogenetic analyses.

\section{Results and Discussion}

General characteristics of the EpapGV genome

The complete EpapGV genome [GenBank: JN408834] was covered 34 times by 454 sequencing. It consists of $119,082 \mathrm{bp}$ in good agreement with the previous estimate of $120.1 \mathrm{kbp}$ based on restriction mapping [19]. Betabaculoviruses have AT-rich genomes ranging between 54.7\% (CpGV) and 67.6\% (CrleGV). The AT content of EpapGV genome is $58.5 \%$. However, no correlation between these data and biological properties has been found thus far.
Analysis of the EpapGV genome sequence led to the identification of 133 putative protein coding genes. The search was restricted to open reading frames starting with a methionine codon, coding for polypeptides of at least 50 amino acid residues (aa) and minimal overlapping of adjacent ORFs. This information comprises $90.94 \%$ of the nucleotide sequence (Additional File 1). The adenine of the granulin start codon was designated nucleotide 1 and the sequence was numbered in the direction of granulin gene transcription, which defined the clockwise orientation of the circular genome map [20]. The putative ORFs were numbered sequentially in this orientation. Seventy-two ORFs were in the same orientation as the granulin ORF, and sixty-one, in the opposite. EpapGV DNA sequence was searched for promoter motifs $150 \mathrm{bp}$ upstream of the starting codon of each ORF. Early promoter motifs including TATA box (TATAWAW, TATAWTW, TATAW) in conjunction with CAKT initiator sequence (INR) [21] were found in the upstream regions of 26 ORFs; 64 ORFs had a late INR motif DTAAG [22] and 11 ORFs had both early and late elements.

\section{Gene content}

The EpapGV genome contains the 31 core genes present in all baculoviruses. The genes were also classified according to their presence in different genera $[23,24]$ (Figure 1).

A distinct feature of the EpapGV genome is that the core gene alkaline nuclease (alk-exo, epap119) is fused in frame with the helicase-2 ORF (epap120). This fusion gene codes for an 886 aa polypeptide with the first 383

Table 1 Completely sequenced Betabaculovirus

\begin{tabular}{|c|c|c|c|c|c|c|c|}
\hline Virus & $\begin{array}{l}\text { Genome } \\
\text { size (bp) }\end{array}$ & $\begin{array}{c}\text { Accesion } \\
\text { number }\end{array}$ & $\begin{array}{l}\text { Annotated } \\
\text { ORFs }\end{array}$ & $\begin{array}{l}\text { Average \% id } \\
\text { with EpapGV }\end{array}$ & Host family & $\begin{array}{c}\text { Pathology } \\
\text { type }\end{array}$ & Reference \\
\hline EpapGV & 119.082 & JN408834 & 133 & - & Tortricidae & $\|$ & [6], this work. \\
\hline AdorGV & 99.657 & AF547984 & 119 & 41.02 & Tortricidae & 1 & {$[7,8]$} \\
\hline AgseGV & 131.680 & AY522332 & 132 & 44.12 & Noctuidae & $\|$ & Xiulian et al., 2004, unpublished \\
\hline ChocGV & 104.710 & DQ333351 & 116 & 44.39 & Tortricidae & $\mathrm{nr}$ & {$[9]$} \\
\hline CrleGV & 110.907 & AY229987 & 128 & 44.25 & Tortricidae & $\|$ & {$[10]$} \\
\hline CpGV & 123.500 & U53466 & 143 & 44.16 & Tortricidae & $\|$ & {$[11]$} \\
\hline HearGV & 169.794 & EU255577 & 179 & 39.71 & Noctuidae & 1 & {$[12]$} \\
\hline PhopGV & 119.217 & AF499596 & 130 & 42.55 & Gelechiidae & $\|$ & Croizier et al., 2002, unpublished \\
\hline PiraGV & 108.592 & NC_013797 & 120 & 44.62 & Pieridae & $\mathrm{nr}$ & {$[13]$} \\
\hline PlxyGV & 100.999 & AF270937 & 120 & 41.01 & Plutellidae & $\|$ & {$[14]$} \\
\hline PsunGV & 176.677 & EU678671 & 183 & 40.17 & Noctuidae & 1 & Li et al., 2008, unpublished \\
\hline SpliGV & 124.121 & DQ288858 & 136 & 40.96 & Noctuidae & $\mathrm{nr}$ & {$[15,16]$} \\
\hline XcenGV & 178.733 & AF162221 & 181 & 39.84 & Noctuidae & 1 & {$[17]$} \\
\hline ClanGV* & 101.487 & NC_015398 & 123 & nd & Notodontidae & $\mathrm{nr}$ & [18] \\
\hline
\end{tabular}

When information is available, GV type pathology is indicated. nr: not reported. $\left(^{*}\right)$ The genome of Clostera anachoreta GV was published [18] after the present work was completed; it was not included in this analysis. 


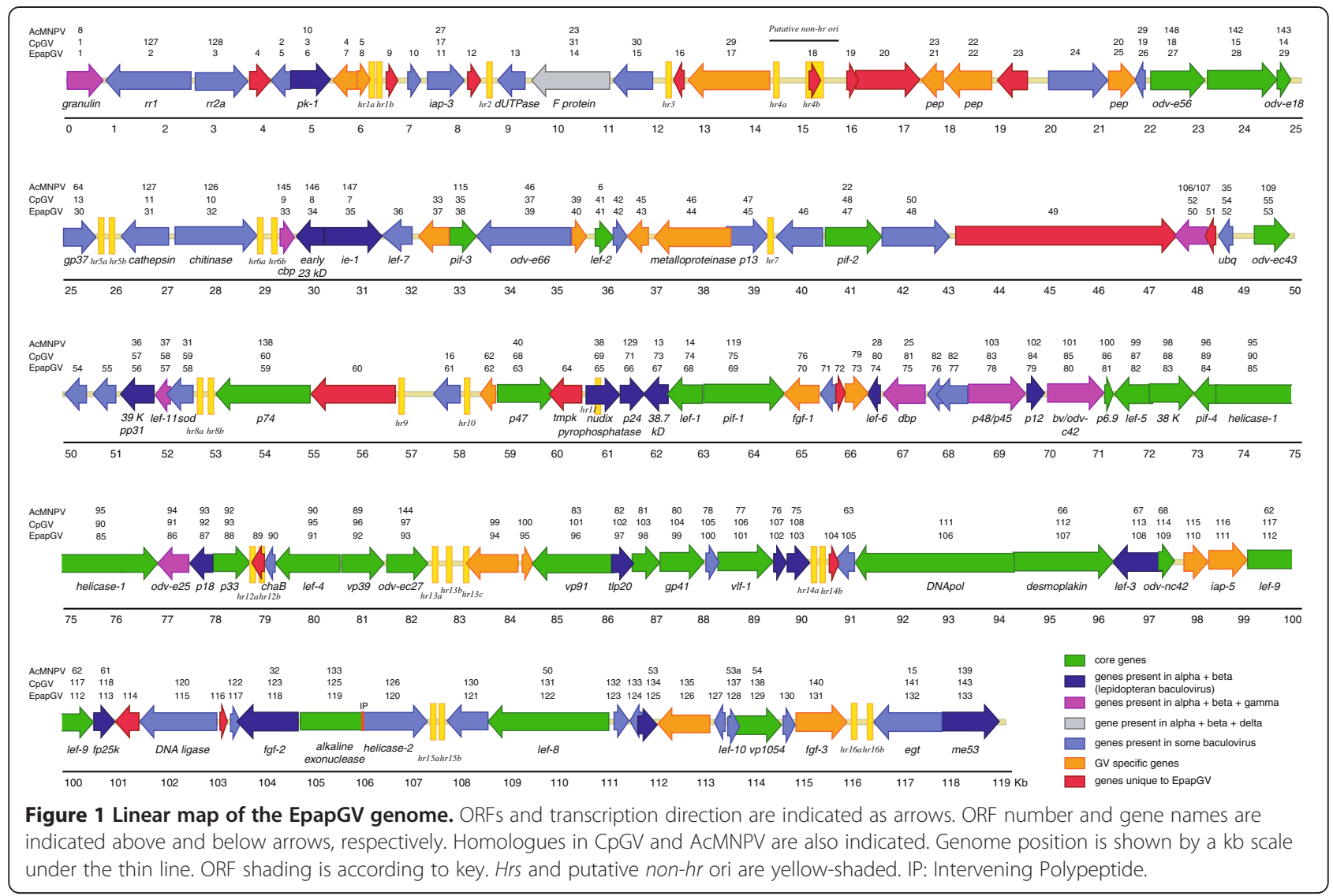

residues homologous to Alk-Exo and the last 456 to Helicase-2. A 47 aa-long intervening polypeptide of unknown origin and without significant sequence similarity to any protein in GenBank was found between the Alk-Exo and the Helicase-2 regions. The intervening polypeptide may act as a low-structure linker between Alk-Exo and Helicase- 2 such that both enzyme domains could fold as if they were independent polypeptides retaining their respective functions (Figure 2 and Additional files 2 and 3). Although this region was confirmed by resequencing, it will be important to study this genomic region in alternative isolates of EpapGV and determine the transcription and translation products in infected larvae. All GVs contain these two genes in the same order, but there are no reports of a fusion. Fusion genes seem to be extremely rare in baculovirus genomes, but there is one report of fused genes encoded by Spodoptera litura NPV: the ubiquitin ORF is fused in frame with $g p 37$ and the fusion protein is proteolytically processed [25].

For two EpapGV ORFs (epap10 and epap130) the BlastP search found homologues in only one member of the Baculoviridae. Epap10 is preceded by early and late promoter motifs and codes for a 90 aa protein that shares $34 \%$ amino acid identity with a 88 aa protein encoded by eppo 28 of Epiphyas postvittana NPV. This
ORF was reported to be unique to EppoNPV and has an early promoter motif [26]. Epap130 codes for a 77 aa protein that matched a 56 aa protein of Spodoptera litura GV (spli32) with $38 \%$ sequence identity according to ClustalW alignment.

ORFs 10, 46, 54, 55 and 105 were found to have homologues in alphabaculovirus genomes but not in other betabaculoviruses. Epap46 is a 306 aa long protein that seemed to be homologous to Spodopera exigua MNPV ORF 30 by BlastP search $(E=0.07)$ although they have very low amino acid identity (12\%). Epap54 (148 aa) and epap55 (157 aa) are both similar to ORF 3 of Adoxophyes honmai NPV (AdhoNPV) and ORF 3 of Adoxophyes orana NPV (AdorNPV). Epap55 shares 32\% identity with the $\mathrm{N}$-terminal portion of AdorNPV ORF 3 and Epap54 is homologous to the C-terminal region of ORF 3 of AdorNPV (34\%) and AdhoNPV (34\%). GV homologues of epap54 and epap55 were found only in AgseGV (Additional File 1). Epap105 is similar to ac63 of Autographa californica MNPV (AcMNPV); their predicted proteins are $28 \%$ identical. Its homologue in Bombyx mori NPV (BmNPV), bm51, was reported to be a structural gene associated with the budded virus (BV) envelope [27], but its deletion resulted in a virus with a phenotype similar to the wild type indicating that it might be a nonessential gene [28]. 


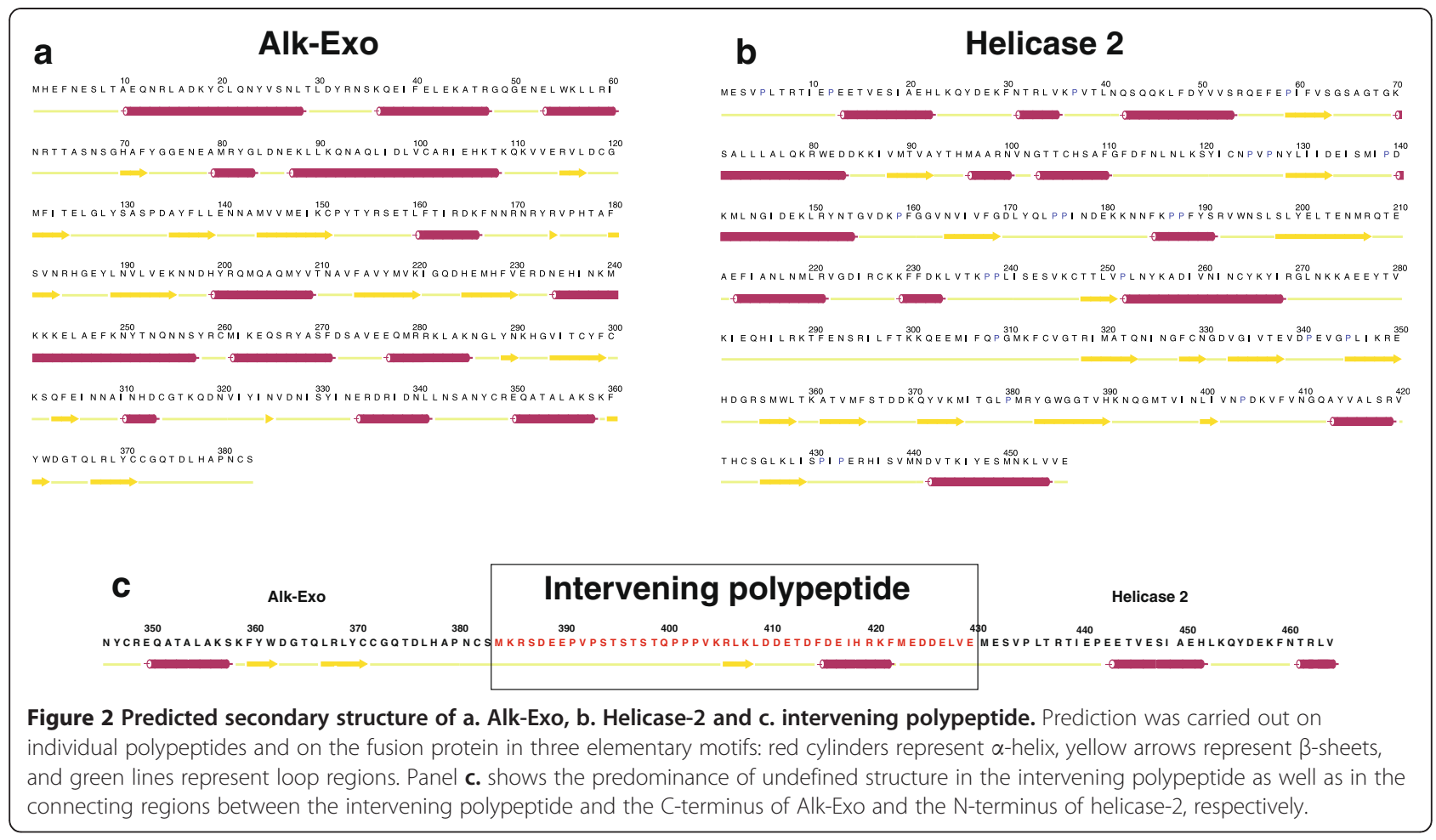

Epap24 codes for a 388 aa long protein that is highly similar to ORF 21 of Cryptophlebia leucotreta GV (CrleGV) according to BlastP search $(\mathrm{E}=4 \mathrm{E}-05)$. Crle21 is a 308 aa predicted protein reported to be similar to Se43 [10]. These proteins share a protein motif of the DUF1383 superfamily. They have homologues in all alphabaculoviruses [28] and studies conducted with a deletion mutant of the homologue in AcMNPV (ac18) indicated that it is not essential for viral replication both in vitro and in vivo, but it may play a role in efficient virus infection in Trichoplusia ni larvae [29]. Homologues of epap24/crle21 were not found in the rest of the granuloviruses.

\section{Transcription genes}

EpapGV DNA codes for the RNA polymerase subunits lef-4 (epap91), lef-9 (epap112), lef-8 (epap122) and $p 47$ (epap63), lef-5 (epap82) and vlf-1 (epap101), present in all baculoviruses. Additional genes related to the transcription process found in all lepidopteran baculovirus were also detected in the EpapGV genome: $39 k / p p 31$ (epap56), lef-6 (epap74), lef-11 (epap57) (present in gammabaculoviruses) and $p k-1$ (epap6). Lef-10, involved in late transcription and present in most alpha- and betabaculoviruses, was also found in EpapGV genome (epap128). Of the baculoviral early transcription genes $i e-0$, ie-1, ie-2 and pe38, only ie-1 (epap35) is present in all GVs and pe38 was found in CpGV, CrleGV, PhopGV and PrGV.

\section{Replication genes}

Genes involved in DNA replication that belong to the core group were found in EpapGV genome: dnapol (epap106), lef-1 (epap68), lef-2 (epap41) and helicase-1 (epap85). and were found in EpapGV and in other lepidopteran baculoviruses are $d b p$ (epap75) (also present in gammabaculoviruses), lef-3 (epap108), ie-1 (epap35), me53 (epap133) and ac38 (epap65). A lef-7 homologue was found in a BlastP search restricted to baculoviruses: the protein encoded by epap36 has a match with PsunGV LEF-7 $(E=0.54)$. This protein was demonstrated to be a baculoviral replication enhancer in AcMNPV [30] and BmNPV [31]. Homologues of this gene are present in group I NPVs, 3 group II NPVs and 3 GVs (XcGV, HearGV [28] and PsunGV).

EpapGV encodes a DNA ligase (epap115) as do other members of the Betabaculovirus genus and three NPVs of group II (LdNPV, LyxyNPV and OrleNPV). This gene seems to be linked to the presence of a second helicase, helicase-2 (epap120) [32], which is fused with alk-exo in EpapGV, but not in the rest of the baculovirus genomes sequenced to date.

\section{Structural genes}

EpapGV genome contains all the structural genes corresponding to the core group as well as the lepidopteran baculovirus genes. The structural core group genes are:
In addition, other genes that belong to this category 
p6.9 (epap81), vp39 (epap92), vp1054 (epap129), vp91 (epap96), gp41 (epap99), odv-ec43 (epap43), odv-e18 (epap29), p74 (epap59), pif-1 (epap69), pif-2 (epap47), pif-3 (epap38); pif-4 (epap84); pif-5/odv-e56 (epap27) and the recently discovered pif-6 [33] (epap109). Lepidopteran-specific baculovirus structural genes include granulin (epap1); 25 k-fp (epap113); odv-e25 (epap86); $b v / o d v-c 42$ (epap80), the last two are also present in gammabaculoviruses. F-protein (epap14) is the only gene shared by alpha-, beta- and deltabaculoviruses. EpapGV contains 42 of the 47 proteins found in the occlusion derived virus (ODV) of PiraGV [34]. Five of these ORFs were only found in betabaculoviruses: epap48, epap 94 , epap95, epap123 and epap126.

\section{Auxiliary genes}

In addition to core gene alk-exo (Epap119), some other auxiliary genes were found in EpapGV genome. Viral ubiquitin (epap52) is present in GVs and all group I alphabaculoviruses. Cathepsin (epap31) and chitinase (epap32) were found in some GVs and in most alphabaculoviruses. These genes are responsible for the liquefaction of the host in the final stage of infection [35,36]. Their activity is readily apparent in E. aporema larvae infected with EpapGV. There is also a gp37 (epap30) homologue, which is present in some GVs and most NPVs. GP37 is homologous to the entomopoxvirus (EPV) fusolin which was shown to form spindle-like structures. These spindles enhance the peroral EPV infection by contributing to disruption of the peritrophic membrane [37]. EpapGV gp37 gene has been characterized and demonstrated to be glycosylated [38]. The EpapGV genome includes three fibroblast growth factor homologues: $f g f-1,-2$ and -3 (epap70, epap118 and epap131, respectively).

The three $f g f$ genes are present in all sequenced GVs but $f g f-2$ is also present in all alphabaculoviruses. It is thought to be implicated in the virus dissemination in the insect host $[39,40]$. Epap58 encodes a superoxide dismutase homologue (sod) which is widely distributed in baculovirus. Its potential role is still unknown and controversial [41].

EpapGV also possesses two iap genes (inhibitors of apoptosis), iap-3 (epap11) and iap-5 (epap111). Iap-5 is only present in betabaculovirus whereas iap-3 is also present in some NPVs. No p35 homologue was found.

\section{Granulovirus-specific genes}

The number of genes considered to be GV-specific has changed in the literature and will be more accurate when more complete genome sequences become available. These genes could be the basis to the differences between granuloviruses and nucleopolyhedroviruses. Taking into account the analyses presented by Lange et al. [10], Wormleaton et al. [7], Escasa et al. [9], Van Oers \& Vlak [42], Miele et al. [23] and the present report, a set of 19 genes has been identified in betabaculovirus genomes which were never found in alpha-, gamma- or deltabaculoviruses (Figure 1, Additional file 1). These are EpapGV ORFs 7, 8, 17, 21, 22, 25, 37, 40, 43, 44 (metalloproteinase), 62, 70 (fgf-1), 73, 94, 95, 110, 111 (iap-5), 126 and 131 ( fgf-3).

Other genes formerly considered as part of the GVspecific set, were dismissed from the list in the present report: CpGV ORFs 30, 32, 45, 50, 56, 77, 82, 119, 121, 122 and 136. All, except cp27, 56, 77, 121 and 136, have homologues in EpapGV but they are absent in some other GV (see Additional file 1).

\section{Unique genes}

Seventeen ORFs appear to be unique to EpapGV compared to the rest of the members of Baculoviridae (ORFs $4,9,12,16,18,19,20,23,49,51,60,64,72,89,104,114$ and 116). Epap4 codes for a 144 aa long protein with a conserved motif (COG5152) in its N-terminal region. This motif is an uncharacterized conserved domain that contains RING and CCCH-type Zn-fingers [43]. An early promoter motif was found 150 nt upstream epap4 ORF. Epap 9 encodes an 81 aa long polypeptide and has no significant BlastP matches. The upstream region contains a GATA motif (TGATAG) and two TATAWAW early promoter elements, but no CAKT INR. Epap12 codes for a 90 aa protein which shares $23 \%$ identity and $43 \%$ similarity with a small portion of a 2123 aa protein of Drosophila ananassae (XP_001953497); however, no speculation on function can be made. Epap16 gives no significant BlastP hit, and has early promoter elements upstream of the first ATG (TATAW + 3 CATT elements). Something similar happens with Epap18 which codes for a hypothetical 76 aa protein and a TATAW element upstream. Epap19 (94 aa) has no significant BlastP hits and has elements of an early promoter. Epap20 (422 aa) has no significant BlastP hits and shows elements of a late promoter. Epap23 codes for a hypothetical protein of 197 aa with no significant similarity with any protein of the GenBank under the control of a putative late promoter and a GATA motif (TGATAG).

Epap49 codes for the longest hypothetical protein of EpapGV genome (1465 aa). As it lacks characteristic promoter elements and exhibits no similarity with other baculovirus genes it is difficult to predict if it is actually transcribed. Epap49 is located between the conserved genes pif-2 (epap47, core gene) and epap50 (homologue to $c p 52$ ). It is worth mentioning that at least in two GVs (HearGV and ChocGV) a similar situation emerged in the same locus. Although a 1144 aa ORF with 27 leucine zippers was initially found in ChocGV, it was not considered a coding sequence but a non- $h r$ ori-like region 
instead; the speculation was based upon its very high AT content (81\%), the lack of homology with baculovirus ORFs, and the possibility of sequencing errors (for further details see Escasa et al., [9]). In contrast, the 1279 aa ORF in HearGV (hear44) was considered a coding sequence resulting from a fusion of the homologues $x c 47$ and $x c 48$ of Xestia c-nigrum GV [12].

Epap51 codes for a 69 aa peptide under the control of an early promoter and showed no significant matches in BlastP search. Two GATA motifs (TGATAT and AGATAG) were also found in the region upstream its ATG. Epap60 (582 aa) shows no significant hits with any protein in the GenBank. TATATAA and TATAA motifs were found upstream the ATG, but without the initiator sequence CAKT, characteristic of early promoters. Epap64 codes for a thymidylate kinase (described below). Epap72 codes for a 61 aa peptide with no significant matches in the GenBank under the control of a putative late promoter which is overlapped with a GATA motif (AGATAAG). Epap89 predicted protein (86 aa) did not have significant BlastP hits either and lacks known promoter motifs except for a TATAAAA sequence 86 nt upstream its ATG overlapped with a GATA motif. Similarly, ORFs 104 (63 aa), 114 (162 aa) and 116 (51 aa) contain TATA box-like motifs upstream the initial ATG and show no significant BlastP hits. Epap114 also presents a ATAAG sequence, and Epap116 a GATA motif (AGATAA).

\section{Nucleotide metabolism genes}

Genes coding for enzymes involved in nucleotide metabolism have been reported in baculovirus genomes. Ribonucleotide reductase (RNR) catalyses the reduction of ribose in ribonucleotide diphosphates to yield deoxyribonucleotides, the building blocks of DNA [44]. In most eukaryotes the active RNR is a tetrameric complex made up of homodimers of two subunits coded by genes $\mathrm{rr} 1$ and $r r 2$, which have been also found in some NPVs and 4. GVs: CpGV, AgseGV, PhopGV and EpapGV (epap2 and epap3). On the other hand, dUTPase catalyses the dephosphorylation of dUTP to yield dUMP. As dUTP can be mutagenic if incorporated in DNA, this enzyme helps to keep levels of dUTP low and prevents its incorporation in DNA, in lieu of dTTP. This gene is present in some NPVs and in the betabaculoviruses AgseGV, SpltGV and EpapGV (Epap13). The presence of $r r 1, r r 2$ and dutpase appears to be linked in the genomes of OpMNPV, SpltNPV, SeMNPV and LdMNPV [32]. This linkage appears in the betabaculoviruses AgseGV and EpapGV but not in SpltGV. Both enzymes participate in the pathway of de novo dTTP biosynthesis (Figure 3a).

EpapGV codes for a novel enzyme in the family Baculoviridae, which also takes part in this pathway: epap64 codes for a predicted 224 aa protein homologous to thymidylate kinase, also known as thymidine monophosphate kinase (TMPK), that catalyses the phosphorylation of dTMP to produce dTDP. BlastP hits included different eukaryotic organisms and several viruses representing the families Poxviridae (Variola Virus), Iridoviridae (Invertebrate iridescent virus 6, II6), Herpesviridae (Cyprinid Herpes 3, CyHV3), Nimaviridae (White Spot Syndrome Virus, WSSV) and Asfaviridae (African swine fever virus, ASFV) that were used in the ClustalW alignment with EpapGV TMPK (Figure 3b). EpapGV TMPK showed the highest identity (40\%) with TMPK from the insect Drosophila ananassae and the least (22\%) with TMPK from ASFV. The degree of identity with the other viruses was 35\% (II6); 32\% (Variola and Vaccinia); and 33\% (WSSV). Besides Baculoviridae, other viral families that encode nucleotide metabolism genes include Herpesviridae, Poxviridae and Asfaviridae. The alphaherpesvirus pyrimidine deoxynucleoside kinase, popularly known as thymidine kinase (TK) phosphorylates a wide range of nucleoside substrates, as well as TMP (TK + TMPK activity), and is responsible for the rise in the TTP pool characteristic of HSV-infected cells [45]. In poxviruses these TK and TMPK activities are present in separate enzymes as happens in cellular organisms. Vaccinia virus TMPK was found to be nonessential for virus replication in cultured cells and able to complement a tmpk-Saccharomyces cerevisiae mutant [46].

The White Spot Syndrome Virus (WSSV; Nimaviridae) genome contains a mosaic gene that encodes a $t k$-tmpk fusion of both homologues, i.e. cellular-type thymidine kinase TK1 and cellular-type TMPK [47]. However, only TK activity, but not TMPK, could be demonstrated for WSSV TK-TMK [48]. TMPK substrate specificity was studied in vaccinia virus and it was found to phosphorylate dTMP, dUMP and, unlike human TMPK, dGMP as well [49]. EpapGV TMPK expression and substrate specificity, as well as its role in infection, remain to be elucidated.

\section{Repeated sequences}

A common feature in baculovirus genomes is the presence of nucleotide sequence repeats known as homologous regions (hrs). These regions function as enhancers of early gene transcription and are thought to play a role as origins of replication. They are characterized by tandem copies of sequence motifs that include an imperfect palindromic core. Although they present significant sequence similarity within a genome they are highly variable when compared between any two different species (Reviewed in [50]).

In a first screening of the EpapGV genome for repeated sequences with Blast2seq we found two palindromic regions, of 128 bp (58352-58479) and 122 bp (116114-116235), respectively. Both sequences are very likely to exist in equilibrium between double stranded DNA and opposite hairpin-loops constituted by 


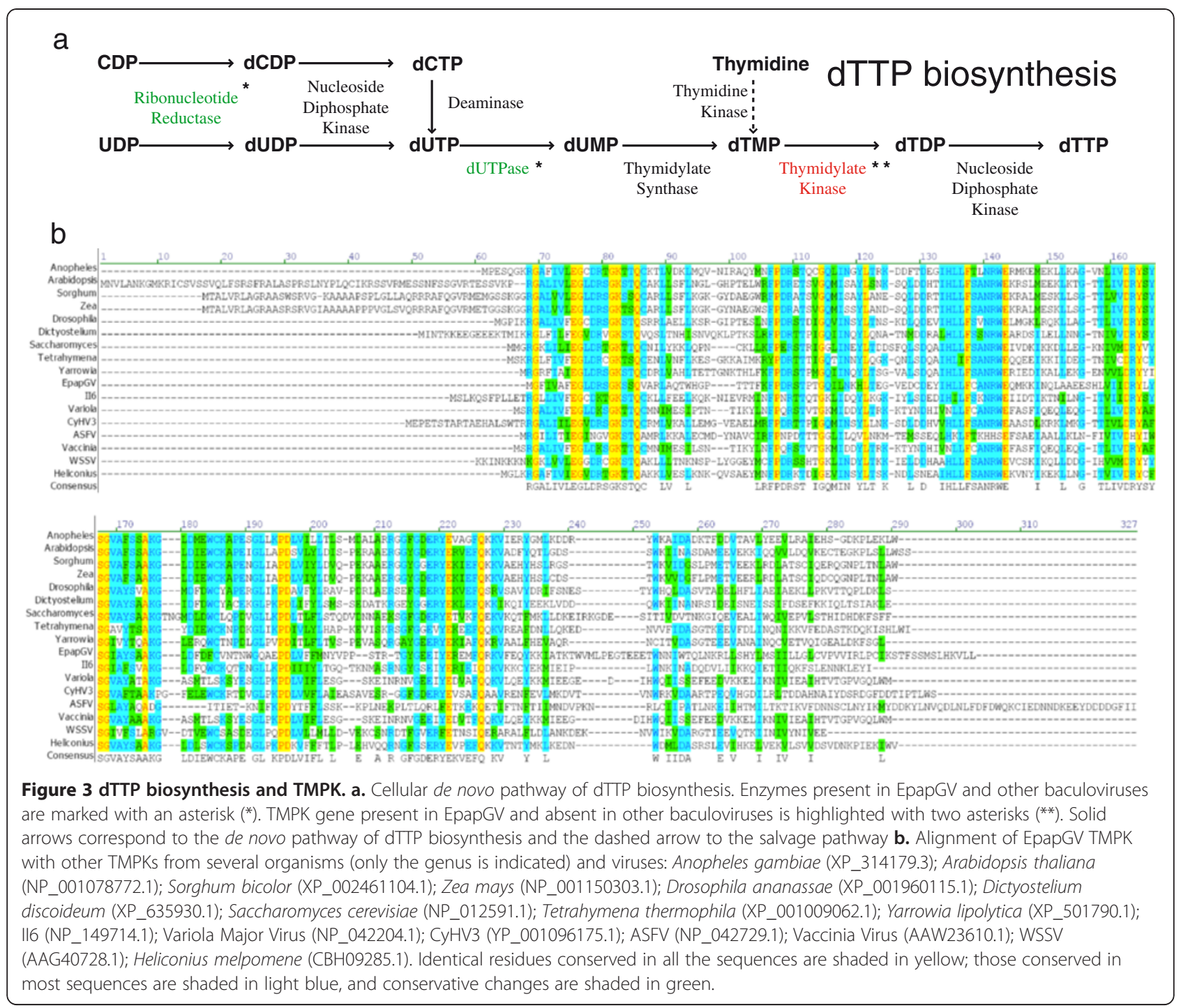

each complementary strand $(h r 10,-75.30 \mathrm{kcal} / \mathrm{mol}$ and hr16a, $-86.50 \mathrm{kcal} / \mathrm{mol}$, respectively) forming a cruciformlike structure (Figure 4a,b). Whether this feature is biologically relevant remains to be elucidated. Using these two sequences as profiles we searched the rest of the genome for similar sequences. Twenty-four AT-rich sequences of similar size were detected dispersed throughout the genome. The alignment of these sequences revealed the presence of conserved palindromes of about $58 \mathrm{bp}$ that correspond with the central part of the two initially identified largest palindromes, with a mean of $70 \%$ AT content. The alignment of these shorter palindromes (Figure $4 \mathrm{~d}$ ) shows that they have an AT rich core flanked by 15 bp conserved inverted repeats (Figure 4d,e). This structure is similar to that of hrs found in all GVs (those sequenced to date) that infect other insects of the Tortricidae family (CpGV, CrleGV, AdorGV, ChocGV): palindromic sequences of about $63-76 \mathrm{bp}$ characterized by conserved blocks of $13 \mathrm{bp}$ located at both ends. These ends were found to be similar in sequence not only among the palindromes of a single genome but among the different genomes, as well [51]. EpapGV palindromic ends are similar to the consensus 13 bp sequence for these GVs, including PhopGV (Figure 4f). PhopGV, that infects a member of the Gelechiidae family but appears in the same clade as these GVs, was also found to have this kind of palindromic repeats, although their length was different (142-320 bp) [51]. Palindromes sharing these features were analyzed in infection-dependent replication assays in cells susceptible to CpGV infection. All 14 CpGV palindromes were found to act as origins of replication of plasmids in infection-dependent assays in Cydia pommonela cells [51,52], whereas the hrs from other GVs tested in the same way did not show this ability, with the only exception of 2 palindromes of the most closely related CpGV virus, CrleGV [51]. 
(See figure on previous page.)

Figure 4 Repetitive sequence analysis. a. Distribution of the putative hrs in the EpapGV genome with their respective palindromes. $\mathbf{b}$. Predicted secondary structure of the two largest palindromes. The central palindrome used in the multiple alignment is boxed with a dashed line. c. Structure of the putative non-hr ori. d. Alignment of all the palindromes excluding hr4b. Genome positions are indicated at both ends of the aligned sequences. Conserved 15 bp ends are boxed. e. Sequence logo performed with the multiple alignment of the palindromes. f. Comparison between consensus EpapGV palindromic ends with the consensus 13 bp ends reported by Hilton \& Winstanley (2008) [51] (see Figure 3 of this reference).

These palindromic sequences are found with a much greater frequency in EpapGV DNA compared to the other tortricid-specific GVs. EpapGV contains 26 palindromes (within 16 hrs), whereas the others have up to 17 palindromes as is the case of CrleGV [51]. In contrast, only four hrs (each one containing only 2-3 direct repeats) were reported in the most recently published betabaculovirus genome sequence (ClanGV; [18]).

There seem to be some conserved locations for the hrs in GV genomes. For example, the region between sod and $p 74$ and downstream of the CpGV ORF 5 [51].

It has been reported for AcMNPV that VLF-1 (a protein present in all the baculoviruses sequenced to date) binds with high affinity to cruciform DNA structures and it was suggested that this may play an important role in the replication/packaging process [53]. These cruciform structures, formed by the two largest palindromes or by the smaller ones interspersed in the EpapGV genome, may as well interact with VLF-1 and play a role in the replication or packaging.

In addition to the 26 palindromes mentioned above, there is a large structure consisting of 327 bp flanked by the $15 \mathrm{bp}$ conserved ends predicted to form the secondary structures shown in Figure 4(a). This structure is located in the $h r 4$ region (including $h r 4 a$ and $h r 4 b$ ), an AT-rich sequence between ORFs 17 and 19. The sequence organization is depicted in Figure 4(c) showing ORF 18 within $h r 4 b$, which also contains two 31 bp direct repeats (A1, A2), and an intergenic region with a second pair of imperfect direct repeats of 79 and 72 bp (B1, B2), respectively. Interestingly, this region is located in the same relative position where a putative non- $h r$ ori was described in CpGV spanning ORFs 24, 25 and 26 (which are absent in EpapGV) [11] and in CrleGV [54].

\section{Relationships with other baculoviruses}

Strong colinearity is observed in granulovirus genomes sequenced to date $[7,10,11,51]$. Baculovirus gene colinearity has been analysed mainly by Gene Parity Plot [55]. In this study we used the Artemis Comparison Tool to analyse the gene synteny of EpapGV compared to all other sequenced GVs and the type species of the Alphabaculovirus genus, AcMNPV. This tool enables to construct synteny maps through a tBlastX comparison between genomes, where inversions are easily detected as well as the different percentages of identities that correlate with different colour intensity. Figure 5 shows the conserved gene colinearity of all 13 sequenced GV genomes and the poorly conserved synteny between GVs and AcMNPV. Notably EpapGV differs from the rest of the GVs by a $c a .20 \mathrm{~kb}$ gene block inversion, as we noted previously in a physical map [19].

Phylogenetic analysis based on 31 concatenated core genes of 58 baculovirus genomes was performed (Figure 6). The obtained cladogram reproduced the grouping of four genera recognized in the current classification of the family [1]. Division in two main groups of the Alphabaculovirus genus agrees with the group I and II. Two clades (Ia and Ib) previously described in group I by using concatenated amino acid sequences of the partial polh/gran, lef-8 and lef-9 genes [56] were also confirmed in our analysis.

As expected, EpapGV grouped in the Betabaculovirus genus. In previous reports it was observed that totricidae and noctuidae specific GVs tend to be in separated groups [56,57]. The cladogram obtained in this work confirms previous observations, and the additional complete genomes considered here allowed the division of betabaculoviruses in two well separated monophyletic clades as reported previously [23]. Clade "a" includes six species: PxGV, AgseGV, SpliGV, PsunGV and XcGV, which were isolated mainly from Noctuidae hosts. PxGV is the exception; its host belongs to the Plutellidae family. Clade "b" includes seven species: EpapGV, AdorGV, PhopGV, CpGV, CrleGV, PiraGV and ChocGV; five of them were isolated from Tortricidae, whereas PiraGV was isolated from Pieridae and PhopGV, from Gelechiidae. EpapGV seems to be the GV isolate closest to the common ancestor of Clade "b". Both clades includes slow killing (type $1 \mathrm{GVs}$ ) and fast killing (type $2 \mathrm{GVs}$ ), reinforcing the concept of that this biological feature is not phylogenetically informative [57].

\section{Conclusions}

In this study the complete genome of EpapGV was characterized. It includes genes that are common to all baculovirus, and others that have been found only in some of the isolates; in addition, it contains 17 genes that are not shared with the rest of the family: 16 with unknown functions, and one encoding a TMPK homologue which may have been captured from of a host genome or a different coinfecting pathogen. Also a set of 19 betabaculovirus-specific genes, was determined. The information collected and analyzed in this study provides ground for further investigations to 


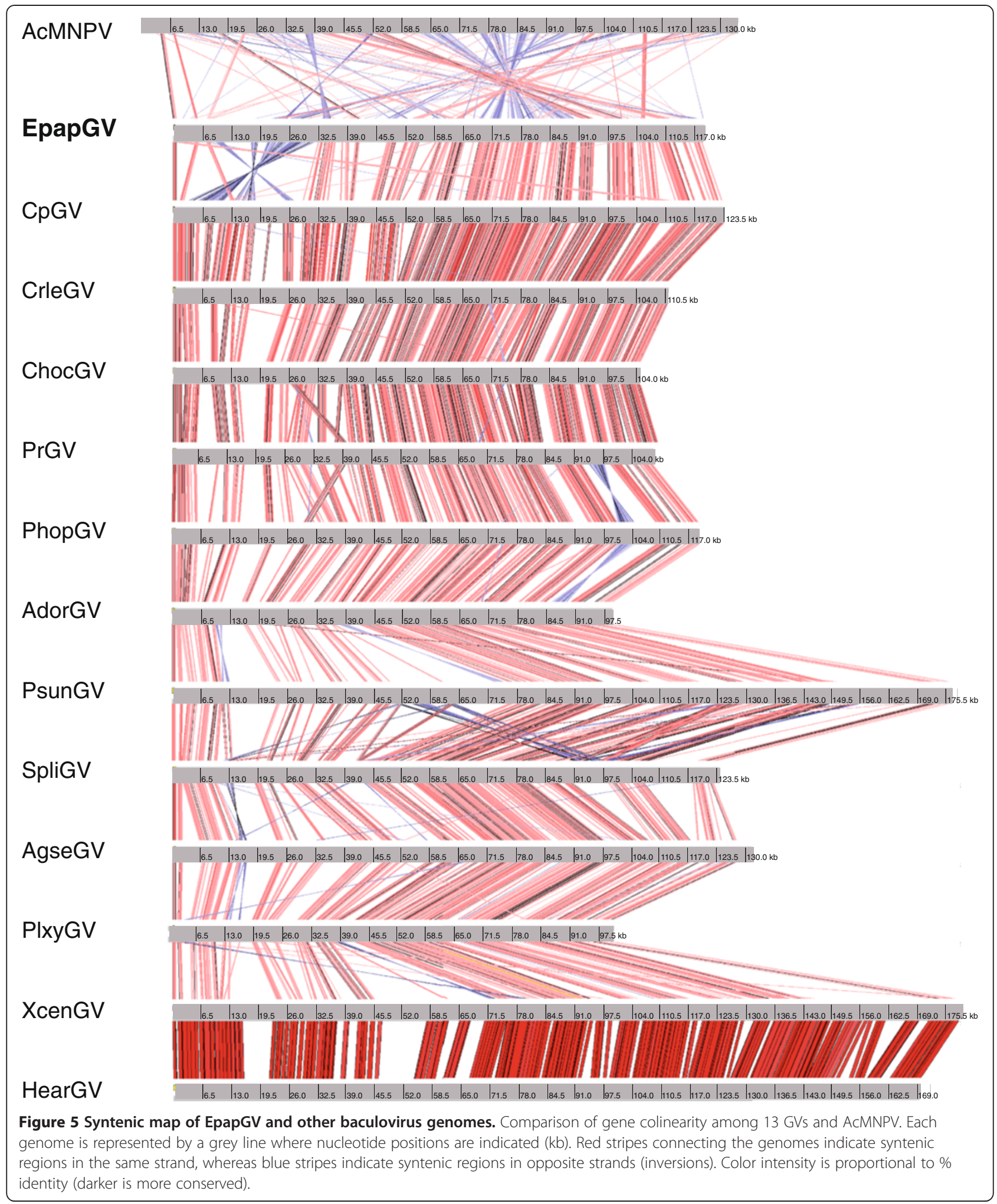

improve the understanding of the molecular steps involved in EpapGV infection.

The analyses of gene order and identity suggest that evolution of baculoviruses occurred via acquisition of both individual genes (or gene fragments) and larger blocks of host DNA sequences followed by events of inversions, deletions, and re-acquisitions of previously lost sequences. Interestingly, the phylogenetic analysis 


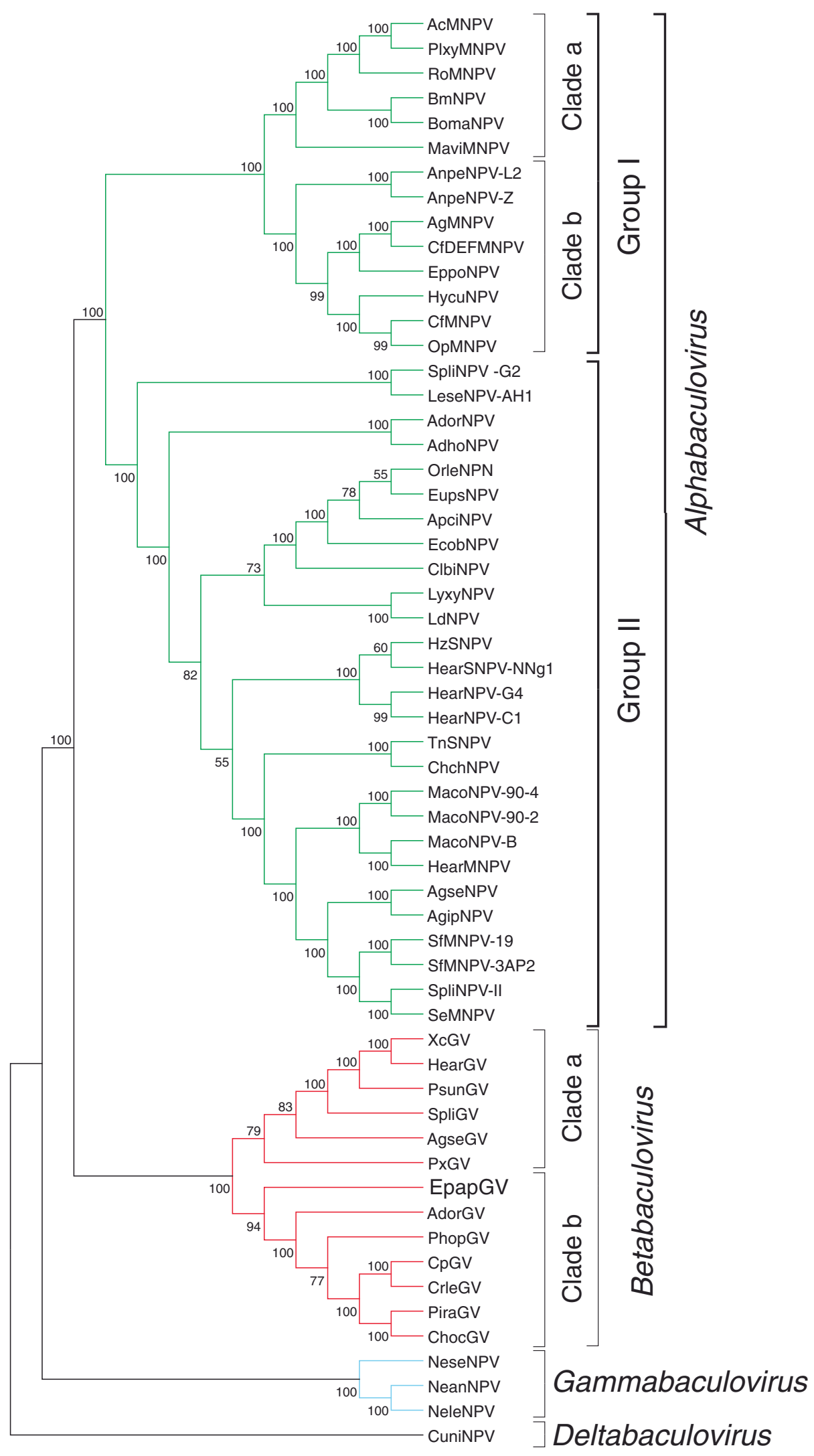

Figure 6 (See legend on next page.) 
(See figure on previous page.)

Figure 6 Phylogenetic tree. Cladogram based on amino acid sequences of 31 core genes obtained from 58 available complete baculoviral genomes were individually aligned, concatenated and a phylogenetic tree was inferred with MEGA 5 program. The four Baculovirus genera and the different subgroups are indicated.

suggested that EpapGV is situated closest to the common ancestor of clade b Betabaculovirus.

\section{Methods}

\section{Insects, virus and viral DNA}

EpapGV was originally isolated from a larva of the bean shoot borer Epinotia aporema collected in Oliveros (Santa Fe, Argentina) [5]. It was amplified allowing fourth instars to feed on artificial diet superficially contaminated with EpapGV occlusion bodies (OBs). Moribund larvae were collected and processed according to Parola et al. [19]: viral DNA was isolated from sucrose gradient purified OBs. Its integrity and identity was checked by restriction digestion and agarose gel electrophoresis.

\section{Nucleotide sequence determination and analysis}

EpapGV genomic DNA was sequenced with the 454 Genome Sequencer (GS) FLX ${ }^{\mathrm{Tm}}$ Standard (Roche) at the Interdisciplinary Center for Biotechnology Research (ICBR), University of Florida (Gainesville, US). De novo assembly was generated on newBler assembler (GS FLX Data Analysis Software).

Open reading frames (ORFs) were identified using VectorNTI software (Invitrogen) and ORF Finder http:// www.ncbi.nlm.nih.gov/gorf/gorf.html [58]. ATG initiated ORFs of at least $150 \mathrm{nt}$ (50 aa) with minimal overlap were selected for further analysis. Homology searches were done using Blast [59]. Percentage identities between homologous genes were obtained by global alignments with ClustalW [60] using default parameters. Early (E) and late (L) Promoter motifs within $150 \mathrm{bp}$ upstream of the putative ORFs were screened. E indicates the presence of a TATA-box (TATAW, TATAWAW, TATAWTW) with a CAKT mRNA start site 20-40 nucleotides downstream; whereas L denotes a DTAAG sequence $[7,10,61]$. Also GATA motifs WGATAR [62] and WGATAY [63] were searched for the unique genes.

Prediction of secondary structure of Alk-Exo_Helicase-2 fused protein was performed with the Jpred3 server [64]; http://www.compbio.dundee.ac.uk/www-jpred/) using default parameters and single sequence submit. Actually, the prediction accuracy of Jnet (main Jpred3 algorithm) raised 81.5\% in blind tests with soluble proteins. C-terminal end of Alk-Exo and N-terminus of Helicase-2 were selected on the basis of multiple alignments of the respective GV proteins.

Repeated sequences were searched first aligning EpapGV genome to itself through Blast2seq program from NCBI [65]. The first hit which corresponds to the $100 \%$ match of the complete genome was ignored and the following hits were used for further analysis. The consensus alignment obtained from two palindromes was used to find similiar sequences along the genome with the VectorNTI program (Invitrogen). The secondary DNA structure prediction of these sequences were performed in the Mfold server of The Vienna RNA website [66]. The alignment of all the palindromes found was performed with ClustalW algorithm with default parameters. The sequence logo of this alignment was carried out at the WebLogo server (http://weblogo.berkeley.edu/) [67].

EpapGV genome was compared with other baculovirus genomes by constructing syntenic maps with the Artemis Comparison Tool (ACT) [68] (The Sanger Institute; http://www.sanger.ac.uk/resources/software/act/), using tBlastX program.

Phylogenetic analysis was performed using 31 core genes from 58 baculovirus genomes (Additional File 4) which were independently aligned using ClustalX program [69], with the following parameters: Pairwise alignment (Gap Open Penalty $=10$, Gap Extension Penalty $=0.1$, protein weight matrix: Blosum 30); Multiple alignment (Gap Open Penalty $=10$, Gap Extension Penalty $=0.05$, protein weight matrix: Blosum series). Then a concatemer was generated by addition of the complete individual alignments and phylogeny was inferred using MEGA 5 program [70] with the following parameters: UPGMA; Bootstrap with 1000 replicates; gap/ Missing data $=$ complete deletion; Model $=$ Amino (Dayhoff Matrix); patterns among sites $=$ Same (Homogeneous); rates among sites $=$ Different $($ Gamma Distributed); gamma parameter $=2.25$. The obtained data was deposited in TreeBASE (http://purl.org/phylo/treebase/phylows /study/ TB2:S12862).

\section{Additional files}

Additional file 1: Predicted ORFs in the genome of EpapGV. This file lists the ORFs predicted in the genome of EpapGV and their homologues in other completely sequenced betabaculoviruses.

Additional file 2: Multiple alignment of betabaculovirus alkaline exonuclease. This file shows the alignment of betabaculovirus alkaline exonuclease amino acid sequences.

Additional file 3: Multiple alignment of betabaculovirus helicase 2. This file shows the alignment of betabaculovirus helicase 2 amino acid sequences.

Additional file 4: Characteristics of baculovirus genomes. This file lists the characteristics of baculovirus genomes, including virus name, genome size, number of ORFs and GeneBank accession number. 


\section{Competing interests}

The authors declare that they have no competing interests.

\section{Authors' contributions}

MLF obtained and purified the viral DNA, analyzed the sequence and wrote the manuscript. RS and MEB participated in viral amplification and purification from insect larvae and revised the manuscript. RS also assisted with the phylogenetic analysis. SH participated in the sequence analysis and revised the manuscript. MFB participated in the hrs analysis and discussion and revised the manuscript. ASC is one of the senior scientists in the project, she provided the viral isolate and equipment for virus and DNA purification, advised on the study and revised the manuscript. PDG participated in the sequence analysis, the phylogenetic tree and supplementary figures, advised on the study and revised the manuscript. VR conceived the study and revised the manuscript. All authors approved the final manuscript.

\section{Authors' information}

MLF and HS hold fellowships from Consejo Nacional de Investigaciones Científicas y Técnicas (CONICET); RS an MEB held fellowships from ANPCyT and CONICET, respectively, when they participated in this study. VR, PDG and MFB hold research career awards from CONICET; ASC and MFB are staff researchers at IMYZA (CICVyA, INTA).

\section{Acknowledgements}

The authors thank Dr. Lorena Passarelli for her helpful comments and suggestions on the manuscript and Mrs. M. Cornacchio and Mrs. D.B. Moreyra for the maintenance of the insect colony at INTA. This work was supported by grants from the Agencia Nacional de Promoción Científica y Tecnológica (ANPCyT) and UNLP to VR and ASC and the Instituto Nacional de Tecnología Agropecuaria (INTA) to ASC.

\section{Author details}

${ }^{1}$ Instituto de Biotecnología y Biología Molecular, Facultad de Ciencias Exactas, Universidad Nacional de La Plata, CONICET, La Plata, Argentina. ${ }^{2}$ Instituto de Microbiología y Zoología Agrícola, INTA, Castelar, Argentina. ${ }^{3}$ Laboratorio de Ingeniería Genética y Biología Celular y Molecular - Area Virosis de Insectos, Departamento de Ciencia y Tecnología, Universidad Nacional de Quilmes, Bernal, Argentina. ${ }^{4}$ Present address: INSERM U748, Institut de Virologie, Faculté de Médecine, Université de Strasbourg, 3 rue Koeberlé, 67000, Strasbourg, France.

Received: 23 November 2011 Accepted: 22 September 2012 Published: 11 October 2012

\section{References}

1. Herniou EA, Arif BM, Becnel JJ, Blissard GW, Bonning B, Harrison R, Jehle JA, Theilmann DA, Vlak JM: Baculoviridae. In Virus taxonomy: classification and nomenclature of viruses: Ninth Report of the International Committee on Taxonomy of Viruses. Edited by King AMQ, Adams MJ, Carstens EB, Lefkowitz EJ. San Diego: Elsevier Academic Press; 2011:163-173.

2. Jehle JA, Blissard GW, Bonning BC, Cory JS, Herniou EA, Rohrmann GF, Theilmann DA, Thiem SM, Vlak JM: On the classification and nomenclature of baculoviruses: a proposal for revision. Arch Virol 2006, 151(7):1257-1266.

3. Carstens $E B$, Ball LA: Ratification vote on taxonomic proposals to the International Committee on Taxonomy of Viruses (2008). Arch Virol 2009, 154(7):1181-1188.

4. Federici BA: Baculovirus Pathogenesis. In The Baculoviruses. Edited by Miller LK. New York and London: Plenum Press; 1997:33-59.

5. Sciocco-Cap A, Parola AD, Goldberg AV, Ghiringhelli PD, Romanowski V: Characterization of a granulovirus isolated from Epinotia aporema Wals. (Lepidoptera: Tortricidae) larvae. Appl Environ Microbiol 2001, 67(8):3702-3706

6. Goldberg AV, Romanowski V, Federici BA, Sciocco de Cap A: Effects of the Epap granulovirus on its host, Epinotia aporema (Lepidoptera: Tortricidae). J Invertebr Pathol 2002, 80(3):148-159.

7. Wormleaton S, Kuzio J, Winstanley D: The complete sequence of the Adoxophyes orana granulovirus genome. Virology 2003, 311(2):350-365.

8. Winstanley D, O'Reilly DR: Granuloviruses. In The Encyclopedia of Virology, vol 1. secondth edition. Edited by Webster R, Granoff A. London: Academic Press; 1999:140-146.
9. Escasa SR, Lauzon HA, Mathur AC, Krell PJ, Arif BM: Sequence analysis of the Choristoneura occidentalis granulovirus genome. J Gen Virol 2006, 87(Pt 7):1917-1933.

10. Lange M, Jehle JA: The genome of the Cryptophlebia leucotreta granulovirus. Virology 2003, 317(2):220-236.

11. Luque $T$, Finch $R$, Crook N, O'Reilly DR, Winstanley D: The complete sequence of the Cydia pomonella granulovirus genome. J Gen Virol 2001, 82(Pt 10):2531-2547.

12. Harrison RL, Popham HJ: Genomic sequence analysis of a granulovirus isolated from the Old World bollworm, Helicoverpa armigera. Virus Genes 2008, 36(3):565-581.

13. Zhang B-Q, Cheng R-L, Wang X-F, Zhang C-X: The Genome of Pieris rapae Granulovirus. J Virol 2012, 86(17):9544.

14. Hashimoto Y, Hayakawa T, Ueno Y, Fujita T, Sano Y, Matsumoto T: Sequence analysis of the Plutella xylostella granulovirus genome. Virology 2000, 275(2):358-372.

15. Wang Y, Choi JY, Roh JY, Woo SD, Jin BR, Je YH: Molecular and phylogenetic characterization of Spodoptera litura granulovirus. J Microbiol 2008, 46(6):704-708.

16. Wang Y, Choi JY, Roh JY, Liu Q, Tao XY, Park JB, Kim JS, Je YH: Genomic sequence analysis of granulovirus isolated from the tobacco cutworm, Spodoptera litura. PLoS. One 2011, 6(11):e28163.

17. Hayakawa T, Ko R, Okano K, Seong SI, Goto C, Maeda S: Sequence analysis of the Xestia c-nigrum granulovirus genome. Virology 1999, 262(2):277-297.

18. Liang Z, Zhang X, Yin X, Cao S, Xu F: Genomic sequencing and analysis of Clostera anachoreta granulovirus. Arch Virol 2011, 156:1185-1198.

19. Parola AD, Manzan MA, Lozano ME, Ghiringhelli PD, Sciocco-Cap A, Romanowski V: Physical and genetic map of Epinotia aporema granulovirus genome. Virus Genes 2002, 25(3):329-341.

20. Vlak JM, Smith GE: Orientation of the genome of Autographa californica nuclear polyhedrosis virus: a proposal. J Virol 1982, 41(3):1118-1121.

21. Friesen PD: Regulation of baculovirus early gene expression. In The Baculoviruses. Edited by Miller LK. New York and London: Plenum Press; 1997:141-170

22. Lu A, Miller LK: Regulation of baculovirus late and very late gene expression. In The Baculoviruses. Edited by Miller LK. New York: Plenum Press; 1997:193-216.

23. Miele SAB, Garavaglia MJ, Belaich MN, Ghiringhelli PD: Baculovirus: molecular insights on their diversity and conservation. Int J Evol Biol 2011, 2011:15.

24. Rohrmann G: Introduction to the baculoviruses, their taxonomy, and evolution. In Baculovirus Molecular Biology. 2nd edition. Bethesda (MD): National Library of Medicine (US), NCBl; 2011.

25. Li Z, Gong Y, Yin C, Wang L, Li C, Pang Y: Characterization of a novel ubiquitin-fusion gene Uba256 from Spodoptera litura nucleopolyhedrovirus. Gene 2003, 303:111-119.

26. Hyink O, Dellow RA, Olsen MJ, Caradoc-Davies KM, Drake K, Herniou EA, Cory JS, O'Reilly DR, Ward VK: Whole genome analysis of the Epiphyas postvittana nucleopolyhedrovirus. J Gen Virol 2002, 83(Pt 4):957-971.

27. Tian CH, Tang XD, Xu HJ, Ge JQ, Miao YG, Zhang CX: Bombyx mori nucleopolyhedrovirus ORF51 encodes a budded virus envelope associated protein. Virus Genes 2009, 38(1):171-177.

28. Rohrmann G: The AcMNPV genome: gene content, conservation, and function. In Baculovirus Molecular Biology. 2nd edition. Bethesda (MD): National Library of Medicine (US), NCBl; 2011.

29. Wang $Y$, Wu W, Li Z, Yuan M, Feng G, Yu Q, Yang K, Pang Y: ac18 is not essential for the propagation of Autographa californica multiple nucleopolyhedrovirus. Virology 2007, 367(1):71-81.

30. Lu A, Miller LK, Krell P, Vlak JM, Rohrmann G: Baculovirus DNA Replication. In The Baculoviruses. Edited by Miller LK. New York and London: Plenum Press; 1997.

31. Gomi S, Zhou CE, Yih W, Majima K, Maeda S: Deletion analysis of four of eighteen late gene expression factor gene homologues of the baculovirus, BmNPV. Virology 1997, 230(1):35-47.

32. Herniou EA, Olszewski JA, Cory JS, O'Reilly DR: The genome sequence and evolution of baculoviruses. Annu Rev Entomol 2003, 48:211-234.

33. Nie $Y$, Fang M, Erlandson MA, Theilmann DA: Analysis of the autographa californica multiple nucleopolyhedrovirus overlapping gene pair lef3 and ac68 reveals that AC68 is a per os infectivity factor and that LEF3 is critical, but not essential, for virus replication. J Virol 2012, 86(7):3985-3994 
34. Wang $X-F$, Zhang B-Q, Xu H-J, Cui Y-J, Xu Y-P, Zhang M-J, Han YS, Lee YS, Bao Y-Y, Zhang C-X: ODV-associated proteins of the pieris rapae granulovirus. J Proteome Res 2011, 10(6):2817-2827.

35. Ohkawa T, Majima K, Maeda S: A cysteine protease encoded by the baculovirus Bombyx mori nuclear polyhedrosis virus. J Virol 1994, 68(10):6619-6625.

36. Slack JM, Kuzio J, Faulkner P: Characterization of v-cath, a cathepsin L-like proteinase expressed by the baculovirus Autographa californica multiple nuclear polyhedrosis virus. J Gen Virol 1995, 76(Pt 5):1091-1098.

37. Mitsuhashi W, Kawakita H, Murakami R, Takemoto Y, Saiki T, Miyamoto K, Wada S: Spindles of an entomopoxvirus facilitate its infection of the host insect by disrupting the peritrophic membrane. J Viro/ 2007 81(8):4235-4243.

38. Salvador R, Ferrelli ML, Berretta MF, Mitsuhashi W, Biedma ME, Romanowsk V, Sciocco-Cap A: Analysis of EpapGV gp37 gene reveals a close relationship between granulovirus and entomopoxvirus. Virus Genes 2012, 45:1-4 doi:10.1007/s11262-012-0800-3.

39. Detvisitsakun C, Cain EL, Passarelli AL: The Autographa californica M nucleopolyhedrovirus fibroblast growth factor accelerates host mortality. Virology 2007, 365(1):70-78

40. Means JC, Passarelli AL: Viral fibroblast growth factor, matrix metalloproteases, and caspases are associated with enhancing systemic infection by baculoviruses. Proc Natl Acad Sci 2010, 107(21):9825-9830.

41. Tomalski MD, Eldridge R, Miller LK: A baculovirus homolog of a $\mathrm{Cu} / \mathrm{Zn}$ superoxide dismutase gene. Virology 1991, 184(1):149-161.

42. van Oers MM, Vlak JM: Baculovirus genomics. Curr Drug Targets 2007, 8(10):1051-1068

43. Marchler-Bauer A, Lu S, Anderson JB, Chitsaz F, Derbyshire MK, DeWeeseScott C, Fong JH, Geer LY, Geer RC, Gonzales NR, et al: CDD: a Conserved Domain Database for the functional annotation of proteins. Nucleic Acids Res 2011, 39(Database issue):D225-D229.

44. Nelson DL, Cox MM: Lehninger Principles of Biochemistry. 5th edition. New York: W. H. Freeman Publishers; 2008.

45. Hay J, Ruyechan W: Alphaherpesvirus DNA replication. In Human Herpesviruses: Biology, Therapy, and Immunoprophylaxis. Edited by Arvin ACFG, Mocarski E, Moore PS, Roizman B, Whitley R, Yamanishi K. Cambridge: Cambridge University Press; 2007.

46. Hughes SJ, Johnston LH, de Carlos A, Smith GL: Vaccinia virus encodes an active thymidylate kinase that complements a cdc8 mutant of Saccharomyces cerevisiae. J Biol Chem 1991, 266(30):20103-20109.

47. Tsai MF, Yu HT, Tzeng HF, Leu JH, Chou CM, Huang CJ, Wang CH, Lin JY, Kou GH, Lo CF: Identification and characterization of a shrimp white spot syndrome virus (WSSV) gene that encodes a novel chimeric polypeptide of cellular-type thymidine kinase and thymidylate kinase. Virology 2000 277(1):100-110.

48. Tzeng H-F, Chang Z-F, Peng S-E, Wang C-H, Lin J-Y, Kou G-H, Lo C-F: Chimeric polypeptide of thymidine kinase and thymidylate kinase of shrimp white spot syndrome virus: thymidine kinase activity of the recombinant protein expressed in a baculovirus/Insect cell system. Virology 2002, 299(2):248-255.

49. Topalis D, Collinet B, Gasse C, Duque L, Balzarini J, Pochet S, Deville-Bonne D: Substrate specificity of vaccinia virus thymidylate kinase. FEBS J 2005, 272(24):6254-6265.

50. Berretta M, Romanowski V: Baculovirus homologous regions (hrs): pleiotropic functional cis elements in viral genomes and insect and mammalian cells. Current Topics in Virology 2008, 7:47-56

51. Hilton S, Winstanley D: The origins of replication of granuloviruses. Arch Virol 2008, 153(8):1527-1535

52. Hilton $S$, Winstanley D: Identification and functional analysis of the origins of DNA replication in the Cydia pomonella granulovirus genome. $J$ Gen Virol 2007, 88(Pt 5):1496-1504.

53. Mikhailov VS, Rohrmann GF: Binding of the baculovirus very late expression factor 1 (VLF-1) to different DNA structures. BMC Mol Biol 2002, 3:14

54. Jehle JA: The expansion of a hypervariable, non-hr ori-like region in the genome of Cryptophlebia leucotreta granulovirus provides in vivo evidence for the utilization of baculovirus non-hr oris during replication. J Gen Virol 2002, 83(Pt 8):2025-2034

55. Hu ZH, Arif BM, Jin F, Martens JW, Chen XW, Sun JS, Zuidema D, Goldbach RW, Vlak JM: Distinct gene arrangement in the Buzura suppressaria single-nucleocapsid nucleopolyhedrovirus genome. J Gen Virol 1998, 79(Pt 11):2841-2851.

56. Jehle JA, Lange M, Wang H, Hu Z, Wang Y, Hauschild R: Molecular identification and phylogenetic analysis of baculoviruses from Lepidoptera. Virology 2006, 346(1):180-193.

57. Herniou EA, Jehle JA: Baculovirus phylogeny and evolution. Curr Drug Targets 2007, 8(10):1043-1050.

58. Wheeler DL, Church DM, Federhen S, Lash AE, Madden TL, Pontius JU, Schuler GD, Schriml LM, Sequeira E, Tatusova TA, et al: Database resources of the National Center for Biotechnology. Nucleic Acids Res 2003, 31(1):28-33.

59. Altschul SF, Gish W, Miller W, Myers EW, Lipman DJ: Basic local alignment search tool. J Mol Biol 1990, 215(3):403-410.

60. Thompson JD, Higgins DG, Gibson TJ: CLUSTAL W: improving the sensitivity of progressive multiple sequence alignment through sequence weighting, position-specific gap penalties and weight matrix choice. Nucleic Acids Res 1994, 22(22):4673-4680

61. Nai YS, Wu CY, Wang TC, Chen YR, Lau WH, Lo CF, Tsai MF, Wang CH: Genomic sequencing and analyses of Lymantria xylina multiple nucleopolyhedrovirus. BMC Genomics 2010, 11:116.

62. Ko $L$, Engel JD: DNA-binding specificities of the GATA transcription factor family. Mol Cell Biol 1993, 13(7):4011-4022.

63. Krappa R, Behn-Krappa A, Jahnel F, Doerfler W, Knebel-Mörsdorf D: Differential factor binding at the promoter of early baculovirus gene PE38 during viral infection: GATA motif is recognized by an insect protein. J Virol 1992, 66(6):3494-3503.

64. Cole C, Barber JD, Barton GJ: The Jpred 3 secondary structure prediction server. Nucleic Acids Res 2008, 36(Web Server issue):W197-W201.

65. Tatusova TA, Madden TL: BLAST 2 Sequences, a new tool for comparing protein and nucleotide sequences. FEMS Microbiol Lett 1999, $174(2) \cdot 247-250$

66. Gruber AR, Lorenz R, Bernhart SH, Neubock R, Hofacker IL: The Vienna RNA websuite. Nucleic Acids Res 2008, 36(Web Server issue):W70-W74.

67. Crooks GE, Hon G, Chandonia JM, Brenner SE: WebLogo: a sequence logo generator. Genome Res 2004, 14(6):1188-1190.

68. Carver TJ, Rutherford KM, Berriman M, Rajandream M-A, Barrell BG, Parkhill J: ACT: the Artemis comparison tool. Bioinformatics 2005, 21(16):3422-3423.

69. Thompson JD, Gibson TJ, Plewniak F, Jeanmougin F, Higgins DG: The CLUSTAL_X windows interface: flexible strategies for multiple sequence alignment aided by quality analysis tools. Nucleic Acids Res 1997, 25(24):4876-4882.

70. Tamura K, Peterson D, Peterson N, Stecher G, Nei M, Kumar S: MEGA5: Molecular Evolutionary Genetics Analysis using maximum likelihood, evolutionary distance, and maximum parsimony methods. Mol Biol Evol 2011, 28(10):2731-2739.

\section{doi:10.1186/1471-2164-13-548}

Cite this article as: Ferrelli et al:: Genome of Epinotia aporema granulovirus (EpapGV), a polyorganotropic fast killing betabaculovirus with a novel thymidylate kinase gene. BMC Genomics 2012 13:548.

\section{Submit your next manuscript to BioMed Central and take full advantage of:}

- Convenient online submission

- Thorough peer review

- No space constraints or color figure charges

- Immediate publication on acceptance

- Inclusion in PubMed, CAS, Scopus and Google Scholar

- Research which is freely available for redistribution 